\title{
A RECONTEXTUALIZAÇÃO DAS TECNOLOGIAS DA INFORMAÇÃO E DA COMUNICAÇÃO NA FORMAÇÃO E NO TRABALHO DOCENTE
}

\author{
RAQUEL GOULART BARRETO*
}

RESUMO: Fundado na análise crítica de discurso, este artigo aborda a recontextualização das tecnologias de informação e comunicação (TIC) na formação e no trabalho docente, considerando as tendências pedagógicas em disputa por hegemonia. Está dividido em quatro seções: (1) princípios básicos da análise crítica de discurso e pontos de entrada; (2) o conceito de recontextualização como chave; (3) ensinar e aprender: entre a substituição tecnológica e a apropriação das TIC; e (4) para além da inovação tecnológica e da "democratização".

Palavras-chave: Formação e trabalho docente. Tecnologias. Dimensão simbólica e material. Políticas educacionais. Ensino-aprendizagem.

\section{THE RECONTEXTUALIZATION OF INFORMATION AND COMMUNICATION TECHNOLOGIES IN TEACHERS TRAINING AND WORK}

ABSTRACT: Grounded on critical discourse analysis, this paper approaches the recontextualization of information and communication technologies (ICT) in teacher training and work by taking into account pedagogical trends in hegemonic struggle. It is divided into four sections: (1) critical discourse analysis principles and entry points; (2) recontextualization as key concept; (3) teaching and learning: between technological substitution and the appropriation of ICT; and (4) beyond technological innovation and 'democratization'.

Key words: Teacher training and work. Technologies. Symbolic and material dimensions. Educational policies. Teaching and learning.

\section{LA RECONTEXTUALISATION DES TECHNOLOGIES DE L'INFORMATION} ET DE LA COMMUNICATION AU SEIN DE LA FORMATION ET DU TRAVAIL DES ENSEIGNANTS

RÉSUMÉ: Fondé sur l'analyse critique du discours, ce texte se penche sur la recontextualisation des technologies de l'information et de la communication (TIC) au sein de la formation et du travail des enseignants, prenant en compte la lutte pour l'hégémonie entre les différentes tendances pédagogiques. Le

* Doutora em Educação e professora do Programa de Pós-Graduação em Educação da Universidade do Estado do Rio de Janeiro. E-mail: raquel@uol.com.br 
texte est présenté en quatre sections: 1) principes de l'analyse critique du discours et point d'approche; 2) le concept de recontextualisation en tant que clé de lecture; 3 ) enseigner et apprendre: entre la substitution technologique et l'appropriation des TIC; et 4) au-delà de l'innovation technologique et de la "démocratisation".

Mots-clés: Formation et travail des enseignants. Technologies. Dimensions symbolique et matérielle. Politiques éducationnelles. Enseignementapprentissage.

\section{Princípios e procedimentos da análise crítica de discurso: pontos de entrada}

$\mathrm{N}$

o título, a amplitude é um imperativo da realidade, considerando as leis, decretos, portarias, resoluções, pareceres, planos e programas que, nas duas últimas décadas, têm produzido mudanças profundas nas condições de produção da formação docente. Mudam os seus marcos regulatórios em vários deslocamentos: do contexto universitário a outros loci e ao privilégio da "modalidade a distância", passando pelo estabelecimento de diretrizes curriculares que favorecem a reconfiguração. No conjunto dos documentos que a sustentam, é atribuída centralidade às tecnologias da informação e da comunicação (TIC).

Neste subtítulo, a adjetivação ("crítica") pretende marcar a diferença em relação ao movimento, cada vez mais presente, de pensar a linguagem desprovida de exterior. Para dimensionar o discurso em relação ao que não o é, Fairclough (2001) propõe uma abordagem tridimensional, tomando-o: na sua materialidade textual; como prática discursiva que compreende produção, distribuição e consumo; e como prática social, "firmemente enraizada em estruturas sociais materiais, concretas, orientando-se para elas" (p. 93). Assim, a abordagem política sustentada pela análise crítica de discurso (ACD) não exclui as questões que adquirem materialidade mais espessa do que a da linguagem. O discurso é pensado como modo de ação que, por sua relação dialética com a estrutura social, permite "investigar as práticas discursivas como formas materiais de ideologia" (p.116).

No que diz respeito à ideologia, a formulação retoma o conceito gramsciano de hegemonia para analisar os movimentos de entrega e resistência dos sujeitos aos sentidos sedimentados e aos deslocamentos possíveis. A busca é pela compreensão dos mecanismos constitutivos da luta pela legitimidade dos diferentes sentidos, já que, em meio aos sentidos historicamente possíveis, um tende a ser mais "lido" que os outros: é formalizado e legitimado, enquanto os demais podem nem ser cogitados. Em outras palavras, na perspectiva histórico-discursiva, a ideologia corresponde à hegemonia do sentido. 
Fairclough (2010, p. 4) também afirma que "os discursos incluem representações de como as coisas são e têm sido, bem como imaginários, entendidos como representações de como as coisas seriam, deveriam ou poderiam ser". Assim, do ponto de vista da $\mathrm{ACD}$, não cabe o movimento de tentar desvelar sentidos que estariam ocultos no que é dito, operando alguma forma do que se poderia chamar de "desideologização", mas de investigar os pressupostos e implícitos do dito: a fundação e o lugar de partida que, justamente por esta condição, podem permanecer intocados.

O discurso constitui matéria a ser investigada no conjunto das suas condições de possibilidade e não apenas como "performatividade", expandida a ponto de lhe atribuir o poder de forjar a realidade por ele referida/representada. O que faz com que as ideias adquiram performatividade é a sua congruência com o que não é discurso; ou seja, com a base da vida material.

Também cabe assinalar que não se trata apenas da linguagem verbal. Considerando as configurações textuais multimidiáticas contemporâneas, são necessários instrumentos afinados para dar conta da articulação de outros materiais semióticos, ou linguagens (em perspectiva não ortodoxa), como imagens e sons, na produção dos sentidos. De qualquer modo, a trajetória analítica é produzida a partir das pistas detectadas na superfície dos textos.

O movimento dos textos para o discurso passa por um corpus de análise, aqui constituído pelo cruzamento de: (1) documentos de organismos internacionais endereçados aos países capitalistas dependentes; (2) políticas educacionais formuladas em nível nacional; (3) produções acadêmicas centradas na incorporação educacional das TIC; e (4) falas produzidas em situações concretas de ensino. Quanto aos pontos de entrada analíticos, compreendem os aspectos semânticos, sintáticos e pragmáticos das práticas discursivas recortadas.

Entre os aspectos semânticos, cabe destacar as escolhas lexicais, compreendendo ressignificações e relexicalizações. As ressignificações compreendem a atribuição de sentidos novos a palavras dicionarizadas, em deslocamentos que tendem a marcar sua inscrição em matrizes outras. Por exemplo, "emancipação" pode perder o sentido coletivo e assumir conotações estritamente individualistas. Já as relexicalizações, ou novas lexicalizações, correspondem à utilização de neologismos ou de termos já cunhados em outras áreas e para outros fins, para dar conta de sentidos que as palavras existentes não expressariam. Assim, por exemplo, as desigualdades entre países tendem a não ser mais representadas como Primeiro e Terceiro Mundo, países desenvolvidos e em desenvolvimento, centrais e periféricos, ricos e pobres; mas como países do Norte e do Sul. Em lugar das demarcações, fica a coordenada geográfica, em um cenário enunciativo marcado pelo privilégio atribuído a diferenças desvinculadas das desigualdades. 
A análise dos processos de ressignificação e relexicalização é imperativa na caracterização dos movimentos de abandono, deslocamento e/ou apropriação de palavras em diferentes contextos e matrizes conceituais, assim como de cunhagem de outras para dar conta de novos aspectos da "realidade". As escolhas lexicais são pontos de entrada fundamentais na análise crítica dos discursos circulantes. Entretanto, não dão conta dos diferentes aspectos envolvidos, sendo um deles as relações estabelecidas entre as escolhas lexicais, marcadas pelas funções sintáticas dos termos nas formulações. É o caso, por exemplo, da "fundamentação" expressa no site da recém-extinta Secretaria de Educação a Distância do MEC: "existência de um sistema tecnológico - cada vez mais barato, acessível e de manuseio mais simples - capaz de" operar transformações. Em deslocamento sintático radical, as TIC são posicionadas como sujeito da formulação.

Além das escolhas lexicais e das relações estabelecidas entre elas, a ACD compreende as relações dos formuladores com as formulações. São os aspectos pragmáticos, representados especialmente pela modalidade assumida, seja ela objetiva ou subjetiva, mais ou menos categórica. No caso do discurso pedagógico, a modalidade discursiva pode (destaque-se a modalidade) ser dimensionada em relação ao caráter de dever ser que o constitui.

Cabe sublinhar, ainda, que este conjunto de procedimentos básicos resulta dos princípios que o sustentam, baseados nas relações entre as configurações textuais, como materiais empíricos dos quais se parte em busca do discurso, e o trabalho analítico propriamente dito. Como processo de trabalho (Marx, 1985), compreende: (1) finalidade; (2) matéria a ser trabalhada; e (3) instrumental/meios para tanto. Não há, portanto, como analisar as práticas discursivas sem pensar as condições históricas e situacionais da sua produção, nos contextos macro e micro, dialeticamente dimensionados. Não há, enfim, uma espécie de manual de pontos de entrada em quaisquer configurações textuais produzidas nos mais diversos contextos. O conjunto de procedimentos aqui destacado já o foi em função do exame do material que constitui este recorte de teorizações, políticas e práticas educacionais, no tempo-espaço.

\section{Recontextualização educacional das TIC}

Neste subtítulo, a adjetivação pode parecer dispensável, já que o conceito foi formulado por Bernstein (1996, p. 259) na perspectiva do discurso pedagógico como "um princípio para apropriar outros discursos e colocá-los numa relação mútua especial, com vistas à sua transmissão e aquisição seletivas". É a partir dele que o autor procede à análise dos processos de "deslocação e relocação", considerando o apagamento da "base social de sua prática (incluindo suas relações de poder)" para a constituição de outra ordem e outros ordenamentos. Entretanto, este texto assume 
a reelaboração do conceito por Fairclough (2006), que o amplia para dar conta não apenas do discurso pedagógico, mas dos vários deslocamentos de um campo para outro, assim como das escalas em que os deslocamentos são promovidos.

No caso das TIC, a própria designação assinala sua produção no interior de outras relações sociais e para outros fins. Não se tratando mais das chamadas "tecnologias educacionais" e considerando as condições de possibilidade do contexto atual, está em jogo a disseminação de discursos para além das fronteiras de estrutura (campo) e de escala (nível). Assim, o processo de recontextualização envolve o movimento da comunicação e da informação e o da lógica dos "negócios" para a educação, com o próprio deslocamento do campo, capitaneado pela Organização Mundial do Comércio (OMC), da condição de política pública, com vistas à internacionalização dos "serviços educacionais" (World Trade Organisation, 2000).

Logo, a recontextualização das TIC pode ser detectada nas formulações das organizações "globais" endereçadas aos Estados nacionais, especialmente quando periféricos, desde que não se perca a perspectiva da complexidade do conceito em leituras lineares e mecânicas, como se o processo não incluísse mediações. Trata-se de uma condição expressa por Fairclough (op. cit., p. 101), ao definir recontextualização como "um fenômeno complexo, envolvendo, para além de uma simples colonização, um processo de apropriação cujas características e resultados dependem das circunstâncias concretas dos diversos contextos".

No que tange aos contextos educacionais, a análise dos modos de recontextualização das TIC, entre políticas e práticas de formação de professores em curso no Brasil, implica a caracterização de dois movimentos antagônicos. De um lado, as TIC representadas como nova força motriz da sociedade, apagando as contradições entre capital e trabalho e os determinantes do desenvolvimento desigual do capitalismo em nível mundial, extrapolando as condições da sua produção, elidindo as múltiplas determinações do real; de outro, as TIC são vistas como produção que não pode ser pensada fora das relações sociais que as engendram.

O primeiro modo de recontextualização das TIC é desencadeado por Adam Schaff, no livro A sociedade informática (1995), com o descentramento da categoria "trabalho" e consequente atribuição do estatuto de revolução às TIC. Desde então, as denominações têm variado: "revolução informacional" (Lojkine, 2002), "sociedade pós-capitalista" (Drucker, 2002) e "sociedade em rede" (Castells, 1999). No cenário mundial, há uma profusão de referências à "sociedade da informação, do conhecimento ou dos saberes", articuladas ao "discurso da globalização". Com todas as suas ambiguidades e sem superar as contradições constitutivas do modo de produção capitalista, desembocam na designação empregada pelo G7, em 1995: "sociedade global da informação". 
A despeito da fragilidade identificável na formulação (Antunes \& Braga, 2009), a alegada centralidade das TIC adquire tal hegemonia que a lógica binária acaba por remeter a oposições como tecnófilos ou tecnófobos, "ciber" ou neoludditas, sendo os primeiros festejados e os últimos desqualificados.

No que concerne ao trabalho e à formação docente, Schaff (1995, p. 72-73) prevê "uma revolução total no sistema de ensino", através da didática propiciada pelos "professores autômatos", como "produto secundário de algo que é muito mais importante neste campo: a tecnologia informática", no contexto de uma nova divisão social entre as pessoas que detêm e as que não detêm a informação, em substituição à propriedade dos meios de produção. Uma proposição que ecoa em formulações como a de um "capitalismo cognitivo" (Galvão, Cocco \& Silva, 2003), centrado no "valor saber".

O modo oposto de objetivação das TIC equivale ao desmonte do primeiro, na crítica ao determinismo tecnológico como extrapolação conceitual indevida, no resgate da própria História da sociedade da informação (Mattelart, 2002). O autor chama atenção para a crença no poder miraculoso das tecnologias informacionais, inscrita no discurso salvador sobre a promessa de concórdia universal, de democratização descentralizada, de justiça social e de prosperidade geral. Acrescenta que o messianismo tem marcado cada um dos saltos no controle do tempo e do espaço, com a renovação da promessa de redenção viabilizada pela amnésia como traço constitutivo dos imaginários sociais da comunicação. Neste tempo-espaço, seu núcleo é a convergência dos discursos apologéticos para atestar o final dos grandes determinantes sociais e econômicos na construção dos modelos de implantação das tecnologias digitais e de suas redes.

Cedendo a palavra a autores dos países ditos do Sul, Canclini (2005) discute as degradações da vida social que não podem ser resolvidas apenas com uma concepção informacional da sociedade; Felinto (2005) aborda a presença não apenas de um imaginário sobre as TIC, mas de um imaginário que é reforçado por elas, na sua conversão em fetiche, como tomada de um meio para a realização de sonhos por sua concretização; e Martin-Barbero (1997, p. 256-257) afirma que a fascinação pelo novo fetiche "encobre a não-contemporaneidade entre objetos e práticas, entre tecnologias e usos, impedindo-nos assim de compreender os sentidos que sua apropriação adquire historicamente".

Os pares acima são fundamentais às várias dimensões da recontextualização das TIC, na perspectiva de que quanto maior a presença da tecnologia, menor a necessidade do trabalho humano, bem como maior a subordinação real do trabalho ao capital e aos que se valem das tecnologias para ampliar as formas de controle do trabalho e dos seus produtos. É fortalecida a racionalidade instrumental, que resulta 
na perda da perspectiva da totalidade do trabalho docente, com o privilégio dos meios, em detrimento das mediações.

A análise da recontextualização educacional das TIC, nas suas dimensões de estrutura e escala, precisa dar conta dos pressupostos e dos implícitos das políticas que a têm sustentado. O mais básico deles pode ser sintetizado em: a presença das TIC, em pacotes ou kits, simplifica os processos de formação e de trabalho docente. Fundada em deslocamentos que esvaziam estes processos, esta simplificação tem favorecido uma cadeia de outras, como ressignificações de ensinar e aprender.

\section{Ensinar e aprender: entre a substituição tecnológica e a apropriação das TIC}

Esta seção é elaborada a partir das ressignificações de ensinar e aprender associadas às TIC, também abreviadas como TDIC, em alusão às tecnologias digitais. Sem pretender dar conta da multiplicidade das novas práticas culturais desenvolvidas com elas, concentra-se nas práticas pedagógicas socialmente promovidas, institucionalizadas.

No cruzamento dos discursos aqui analisados, está em cena uma interlocução assimétrica, a ser discutida com base na "dualidade escolar" (Gramsci, 1991), caracterizada como a coexistência de projetos de educação diferenciados para classes sociais desiguais, a serviço da manutenção da ordem hegemônica. Em outras palavras, não se trata apenas do lugar das TIC na preservação dos poderes econômicos e políticos constituídos, mas do aprofundamento da divisão entre possuidores e despossuídos, nos níveis macro e micro.

Neste ponto, duas tendências articuladas merecem destaque: ensinar (ensino) é um termo cada vez menos presente, ao passo que aprender (aprendizagem) é uma escolha lexical cada vez mais recorrente, acompanhada de adjetivos que remetem a diferenciações de ordem operacional. A primeira pode ser constatada através de simples levantamentos de frequência, enquanto a segunda suscita a discussão do privilégio da técnica como opção política, modalizada pelo acréscimo de adjetivos, como estratégia discursiva. É o que ocorre, por exemplo, em "ensino presencial físico".

Do ponto de vista da sua aplicação estratégica, a Lei de Diretrizes e Bases (LDB) tem como exemplo emblemático a introdução do ensino a distância (EaD), que ocorre na seção III, artigo 32, parágrafo $4^{\circ}$ : “O ensino fundamental será presencial, sendo o ensino a distância utilizado como complementação da aprendizagem ou em situações emergenciais". Sem discutir a polissemia da última expressão, o EaD é introduzido pelo seu contraponto, cuja adjetivação ("presencial"), até então desnecessária, assume caráter legitimador. 
Do ponto de vista epistemológico, o "novo paradigma" quebra a unidade, graficamente representada pelo hífen (ensino-aprendizagem). Deixa de contemplar o ensino, concentrando-se na aprendizagem ressignificada. Ademais, as relações entre os termos podem ser alteradas, como no documento do Banco Mundial (2003), em que a seção intitulada "Usando a tecnologia para transformar a aprendizagem" promove inversão a ser destacada: "a aprendizagem precisa se tornar mais flexível e diferenciada para permitir mecanismos de distribuição (delivery) alternativos" (p. 65). Logo, não se trata de propostas de ensino baseadas em alternativas teóricometodológicas para favorecer a aprendizagem, mas da regulação desta pelos mecanismos de "distribuição", considerando que "a emergência de novos fornecedores, oferecendo serviços diferentes de maneiras diferentes, representa uma oportunidade para os países em desenvolvimento" (p. 55).

Também é digna de nota a recorrência da palavra "acesso", associada não apenas à informação tomada como conhecimento, mas à "aprendizagem”, em construção que sugere deslocamento radical: a aprendizagem não mais como processo interno, deslocada para a condição de "produto dado", a ser acessado. É a celebração de uma espécie de aprendizagem sem ensino: como "autoaprendizagem" ou aprendizagem mediada pelas TIC, estas frequentemente representadas como dispensando a intervenção humana.

Nos discursos acadêmicos acerca da formação de professores, no contexto da pesquisa "Estado do Conhecimento em Educação e Tecnologia" (Barreto et al., 2006), também pode ser detectada uma tendência à celebração da aprendizagem desvinculada do ensino, com pelo menos duas implicações: (1) a ressignificação do trabalho docente, em um cenário marcado pelo protagonismo dos tecnólogos e pela presença de tutores, facilitadores, animadores, entre outras denominações; e (2) a perspectiva da desterritorialização da escola.

A primeira implicação coloca em xeque o pressuposto da presença das TIC como simplificação do trabalho docente, evidenciando esvaziamento e precarização. Assim, a parte substantiva da expressão "trabalho docente" tende a ser substituída por "atividade", "tarefa" etc. A formação inicial tende a corresponder à "certificação" e a continuada, à "qualificação", "capacitação", "treinamento" ou "reciclagem". A pesquisa pode ser reduzida à "prática investigativa". O professor recebe designações como as já citadas: "tutor", "animador", "facilitador" e "monitor", nas muitas relexicalizações que conformam o quadro da redução.

A segunda implicação é expressa pelo deslocamento de um mote conhecido: de "não se aprende somente na escola" para "não se aprende na escola". Com a supressão, a tendência é supor uma relação bastante peculiar entre educação e tecnologias, não remetendo à recontextualização das últimas, mas à negação da escola 
como espaço privilegiado da primeira. Uma tendência que também está inscrita em documento recente do Banco Mundial (World Bank, 2011, p. 6), com o destaque, gráfico inclusive, de que "para a maioria dos alunos, o aumento da escolarização não tem resultado em mais aprendizagem".

Têm sido convergentes os discursos que não apenas apostam nos materiais "autoinstrucionais", mas revisitam propostas, como a de Illich (1973), de uma sociedade sem escolas (título em português), apontando para a desescolarização da sociedade (título original), no cenário neotecnicista atual, aliando a sofisticação tecnológica às ressignificações de ensinar e aprender.

Na Revista da Cepal-Unesco, autores como Labarca (1995) não têm hesitado em recomendar alternativas para os contextos em que o acesso às TIC é mais difícil, como a utilização de materiais impressos, desde que produzidos em nível central e distribuídos aos professores, acompanhados de algum tipo de variação em torno de manuais de instrução: pacotes e modos de usar. Central, de fato, é a organização do ensino a partir de competências a serem submetidas a formas de avaliação unificada. Assim, as TIC são recontextualizadas em uma espécie de "pedagogia de resultados" (Saviani, 2007b, p. 1.253).

Também há programas recentes, como "Padrões de competências em TIC para professores" (Unesco, 2009), com o discurso de que "os professores precisam estar preparados para ofertar autonomia a seus alunos com as vantagens que a tecnologia pode trazer" (p. 1). Entre a autonomia ofertada e o que a tecnologia traz, a qualificação e a posição de sujeito merecem ser sublinhadas. Obviamente, sem defender a incompetência, a questão é, para além da discussão acerca dos pressupostos que sustentam a sua tomada como princípio de organização curricular, a redução do horizonte assumido. Se a formação de professores baseada em competências supõe que o ensino possa ser decomposto em habilidades e competências básicas consensuais, cujo somatório corresponderia ao desempenho "desejável", neste caso elas orbitam em torno das TIC.

As questões relativas à recontextualização das TIC tendem a ficar circunscritas ao achatamento da oposição do "ensino presencial" ao "ensino a distância" $(\mathrm{EaD})$, passando pelo recurso à qualificação "semipresencial" no preenchimento dos espaços entre eles, ou, ainda, pelo apelo ao "ensino virtual": e-learning, b-learning, m-learning, entre outros. Por sua vez, as abordagens centradas no modus operandi não têm favorecido a captação de nuanças em diferentes dimensões dos variados contextos e circunstâncias. Daí a importância da expressão "substituição tecnológica total ou parcial" para a reflexão acerca do caminho a ser percorrido no sentido da apropriação das TIC nos processos de ensinar-aprender, no enfrentamento da expropriação do conhecimento do professor. 
Sem dúvida, a substituição total é mais facilmente demarcável, na medida em que o professor é literalmente retirado da cena pedagógica, enquanto na parcial seu apagamento é passível de discussão, em especial nas configurações mais sofisticadas, menos visíveis. De todo modo, as duas podem favorecer a abordagem da totalidade, afastando dois riscos: (1) o de que, de novo, seja focalizada apenas a dimensão técnica, desta feita restrita ao instrumental utilizado; e (2) o de que as razões mercadológicas obliterem as pedagógicas.

Nesta última hipótese, as TIC são inscritas diretamente em termos de custobenefício. Retomando Labarca (op. cit.), é possível detectar a ressignificação da própria tecnologia, como combinação de recursos materiais e humanos. Nesses termos, o professor é sempre a tecnologia mais cara: exige um longo processo de formação, atende a um número limitado de alunos, deseja exercer seus direitos trabalhistas, precisa de tempo para preparar aulas, fazer avaliações, por exemplo, tornando mais rentável o investimento inicial maciço em recursos materiais que possam ser reproduzidos para um número ilimitado de alunos.

Com as TIC, é possível ampliar o acesso à educação e, ao mesmo tempo, reduzir o seu custo. Como observa Galeano (2006), a tecnologia, que aboliu as distâncias, permite agora que o monopólio econômico reconfigure a competição entre países e pessoas: "quem oferece mais em troca de menos", "quem trabalha o dobro em troca da metade" (p. 75).

Com a expropriação do conhecimento do professor atingindo níveis até então impensáveis, é preciso investigar o que a torna viável: as suas condições de possibilidade. Não bastam as que presidem o silêncio acerca da aliança entre tecnologias, informação e mercado. É necessário compreender as razões pelas quais a recontextualização das TIC não tem remetido à sua apropriação pelos sujeitos. Para tanto, cabe considerar as inversões caracterizadas por Chauí (1999): a substituição da lógica da produção pela da circulação e da lógica do trabalho pela da comunicação, no enredo da compressão tempo-espaço.

No que diz respeito aos professores, é importante a análise da sua imagem construída pelo avesso, inscrita em uma espécie de "discurso da falta" que, formulado a partir de um viés abstracionista, concebe escolas e professores em termos negativos. Deixando de considerá-los nas interrelações concretas que constituem as práticas pedagógicas, abre espaço para propostas de preenchimento através de um conjunto multiplicável de novidades, sempre postas como positivas. Em nome da fragilidade associada à formação profissional, o "discurso da falta" serve para legitimar a substituição tecnológica.

Tende a não haver espaço para as vozes de professores e alunos nas formulações que ignoram as condições concretas de produção das práticas de ensinar e 
aprender. Nas palavras de uma professora de escola pública: “Tem uma reunião depois de amanhã para falar da nova proposta, dos equipamentos. Acho que pode ter coisas interessantes sim. O problema é que eles querem tudo ao mesmo tempo agora". A reunião é para que as autoridades falem e para que as professoras ouçam e apliquem. Traz a falta do direito de ser, de fato, ouvido(a), ao falar de lugares desiguais e posições diferentes, como na pergunta formulada timidamente por uma aluna, após um curta-metragem: "Mas, eu posso falar mesmo o que é que eu acho?"; e na exclamação entreouvida de outro aluno, à espera da abertura do laboratório de informática na mesma escola: "Que pobreza! Nem tem um computador pra cada um..." (Barreto, 2011, p. 350).

Tomando como pergunta a exclamação acima, o diagnóstico da "pobreza", mais ou menos explícito nas políticas de formação, tende a se concentrar no que falta aos professores e nos professores que faltam. Para dar conta dos últimos, o MEC desenvolveu "campanhas de valorização" veiculadas na mídia em geral, com o slogan: "Seja um professor!". Quanto ao que falta aos professores, propostas de preenchimento são objetivadas a seguir.

\section{Para além da inovação tecnológica e da "democratização"}

Esta última seção compreende a tentativa de sistematizar as aparentes contradições que têm sustentado as propostas de recontextualização educacional das TIC: (1) preenchimento das faltas através da formação aligeirada; (2) movimento de expansão, redução/adição e subtração; e (3) democratização e aprofundamento das desigualdades. $\mathrm{O}$ foco está posto nas relações entre elas, considerando a sua inscrição no quadro das tendências discursivas contemporâneas, com o objetivo maior de remeter a propostas para superar uma cadeia de simplificações associadas às TIC na formação de professores.

Como exemplo, o Plano Nacional de Educação (PNE) da última década (Lei n. 10.172/2001) dedicou todo um capítulo a uma relação invertida: "Educação a distância e tecnologias educacionais". Cabe acrescentar que, ao mesmo tempo em que restringiu a recontextualização das TIC, limitando-as à condição de suportes para a veiculação de materiais ditos autoinstrucionais, o texto não deixou de remeter à sua concepção como estratégia de "universalização e democratização do ensino", chegando a mencionar a "construção de um novo paradigma da educação a distância" (PNE, 2001, p. 42). A partir do pressuposto de que "quanto mais meios disponíveis, menos mediações são necessárias", previu, ainda, entre os "Objetivos e Metas": "Iniciar, logo após a aprovação do Plano, a oferta de cursos a distância, em nível superior, especialmente na área de formação de professores para a educação básica" (idem, ibid., p. 44). 
Mesmo sem entrar aqui na discussão dos aspectos substantivos da formação a distância, esta destinação prioritária merece ser sublinhada, assim como os esforços atuais para que, no próximo PNE, a formação inicial seja presencial, admitida a exceção para os/as profissionais da educação em exercício nas regiões onde não haja cursos presenciais, sendo a sua oferta "desenvolvida sob rígida regulamentação, acompanhamento e avaliação" (Conae, 2010, p. 83). A formulação indica a retomada do sentido de distância física e a preocupação com o aligeiramento a que a formação a distância tem sido submetida, haja vista a recente multiplicação dos polos, assim como a voracidade com que têm sido abocanhadas as fatias mais baratas de um ensino superior esvaziado, no deslocamento do seu sentido social para a condição de mercadoria negociável no mercado.

Está no centro da cena discursiva a "comodificação", definida por Fairclough (2001, p. 255) como "processo pelo qual os domínios e as instituições sociais, cujo propósito não seja produzir mercadorias no sentido econômico restrito de artigos para venda, vêm não obstante a ser organizados e definidos em termos de produção, distribuição e consumo de mercadorias". Nela, três facetas merecem destaque: (1) sua incorporação ao conjunto das práticas discursivas, no próprio meio acadêmico, através de termos tomados de empréstimo à área comercial; (2) sua derivação de commodities: mercadorias com baixo valor agregado; e (3) sua operação de modo orgânico com o padrão de acumulação do estágio atual do capitalismo.

No cenário internacional, o discurso do Banco Mundial destaca: “o horizonte educacional transformado pela globalização e pela revolução das TIC" (World Bank, 2002, p. 65); e as forças do mercado "assumindo papel cada vez mais importante na educação mundial” (idem, 2003, p. 19). No primeiro excerto, é marcante a "nominalização" (Fairclough, op. cit., p. 227), que reduz processos a nomes, e a modalidade categórica é inexorável. Em ambos, os agentes não são humanos; são inanimados.

Um terceiro excerto pode ser uma chave importante para a abordagem da "democratização" a ser mantida entre aspas. No documento de 2002, "o perigo real do aumento da lacuna digital entre as nações e dentro delas" (World Bank, op. cit., p. 14) traduz de outro modo a eliminação de barreiras e o preenchimento de lacunas: um processo de mão única, a depender do agente e do perigo. Há a referência ao "mercado mundial" (World Bank, 2000, p. 71) e às "lojas globais do conhecimento" (idem, 2002, p. 24). No mercado, "os países em desenvolvimento também podem se beneficiar muito com instrumental tecnológico para pesquisa, de segunda mão, mas não obsoleto, que pode ser comprado" (idem, 2000, p. 71). Já as lojas podem ser acessadas e a mercadoria-conhecimento adaptada para uso local. Em ambos os casos, as TIC perdem a condição substantiva, convertidas em adjetivo para inovação. É a inovação tecnológica (Leher, 2004) como barreira interposta aos países ditos do 
Sul, restringindo-os a "disciplinas e campos congruentes com as oportunidades de inovação emergentes no contexto local" (World Bank, 2002, p. 132).

No contexto brasileiro, a nova designação do Ministério da Ciência, Tecnologia e Inovação está oficializada. Proliferam programas que visam à utilização intensiva das TIC, formulados em vários âmbitos e por diferentes sujeitos, tendo em comum a lógica do mercado, como o Programa de Desenvolvimento da Educação (PDE) que, incorporando as metas da organização de empresários “Todos pela Educação” (TPE), remete ao plano do "Compromisso de Todos pela Educação", constituindo "um grande guarda-chuva que abriga praticamente todos os programas em desenvolvimento pelo MEC" (Saviani, 2007b, p. 1233). No Projeto de Lei n. 8.035/2010 (PNE), é marcante a recorrência da menção às TIC como estratégia para a consecução das mais diversas metas, com ênfase na correção de fluxo, "com vistas à redução da desigualdade educacional" (p. 19). No portal do MEC, o acesso passa por imagens-chave. Algumas são sazonais, como remissão a programas específicos, enquanto a primeira, constante, abre para o todo a partir da palavra-chave: educação. Na imagem, um menino, de provável ascendência indígena, diante de um computador, posa para a foto. Mudando de posição, sorri tanto para a esquerda quanto para a direita. Nos mais variados discursos, especialmente no publicitário, tende a ser celebrada a democratização do acesso à informação que, por sua vez, é posta como sinônimo de conhecimento.

Neste conjunto, aparentemente caótico, está a renovação do sonho de Alexandria, da reunião dos saberes produzidos pela humanidade, agora depositado em sites como o Google. Ao mesmo tempo, patentes e leis de propriedade intelectual protegem o conhecimento estratégico. Qualquer acesso a um computador parece autorizar o uso da expressão "inclusão digital" e, por extensão, da "inclusão social". Um laboratório de informática pode ser o espaço da escola onde os computadores existentes são depositados, mesmo não estando conectados entre si ou à internet. Há as escolas pobres, para alunos idem. E são a maioria.

Pensar as TIC no processo de ensinar-aprender extrapola a sua simples presença, como condição necessária, mas não suficiente, para o encaminhamento das questões relativas à sua apropriação. São aqui assumidos dois pressupostos. O primeiro deles diz respeito à defesa do acesso às TIC, assim como a todos os produtos do trabalho humano. Entretanto, a defesa do direito de acesso aos bens culturais não pode descambar para simplificações que o descaracterizem. Logo, o segundo equivale à ruptura do silêncio quanto às diferenças e desigualdades reinstauradas pelos modos como o acesso é produzido e pelos sentidos que lhe são atribuídos. A noção de "divisor digital", ressignificada, não se coaduna mais com a distinção simples entre os que têm e os que não têm acesso às TIC.

Entretanto, a ausência das TIC tem servido de argumento para explicar o fracasso na "pedagogia dos resultados" e de justificativa para o fornecimento de kits 
tecnológicos acompanhados de manuais de uso. É a redução de professores e alunos a usuários/consumidores. Quanto aos kits, têm sido cada vez mais assumidos por grandes corporações, como o Sistema Educacional Brasileiro, pertencente ao grupo Pearson (assim como o Financial Times e o Wall Street Journal), Kroton, Abril, entre outros, monopolizando o que é dado a pensar nas escolas.

Na perspectiva de favorecer os mecanismos de "distribuição" dos kits, as políticas têm priorizado programas como "Um computador por aluno" (UCA), versão nacional do homônimo OLPC (One Laptop Per Child) e, mais recentemente, de tablets para o ensino médio. Podem mudar os artefatos tecnológicos, mas não a proposta de substituição tecnológica, seja ela total ou parcial.

Por outro lado, ainda são muito poucos, comparativamente, os discursos produzidos do lugar da escola, dando conta da recontextualização das TIC nas práticas pedagógicas, não como novos meios para executar as "mesmas" tarefas, mas para a instauração de diferenças qualitativas no trabalho docente: formulações que se contraponham à alegada centralidade das TIC e à imposição de modelos supostamente aplicáveis a quaisquer situações.

Na medida em que práticas significativas são produzidas nas escolas e alternativas de formação docente são forjadas nas universidades, é preciso socializar estas produções, formalizando propostas contra-hegemônicas de apropriação das TIC, em movimento "de baixo para cima". Afinal, as TIC podem favorecer dimensões de ensinar e aprender, desde que o acesso à informação não seja tomado pela totalidade destes processos.

O tipo de metonímia que consiste na tomada da parte pelo todo tem sido uma constante no encaminhamento das questões relacionadas à recontextualização das TIC. O mesmo ocorre com as adições formais, como a adjetivação sucessiva de substantivos ressignificados por esvaziamento. Nesses termos, "mais pode ser igual a menos": a formação aligeirada como preenchimento, a expansão que reduz e a "democratização" que aprofunda as desigualdades.

Pensar a formação de professores neste tempo-espaço implica superar as elaborações fundadas nas TIC, no sentido do centramento do processo de trabalho, abrangendo finalidade, matéria e instrumentos/meios, tendo como horizonte as tendências pedagógicas em disputa por hegemonia. Saviani (2007a), ao caracterizar duas grandes tendências, do ponto de vista da pedagogia, trabalha com palavras-chave deste texto: ensino e aprendizagem. Situa o ensino com ênfase no polo da teoria e a aprendizagem, no da prática, sem pensá-los a partir da lógica formal, mas como opostos que se incluem. Esclarece que "o ativismo é a 'prática' sem teoria e o verbalismo é a 'teoria' sem a prática" (p. 109). 
Também é preciso reconhecer que a dialética teoria-prática tende a ser encarada com certa desconfiança, parecendo evocar clichês associados à sua dicotomização: "a teoria na prática é outra". No sentido da sua superação, é a defesa da vivência da formação como construção teórica que mobiliza diferentes saberes, assumindo a prática "como seu fundamento, finalidade e critério de verdade" (Saviani, op. cit., p. 108). Uma proposta que retoma e remete à dialética formação-trabalho docente.

Para a construção e a socialização de propostas que se contraponham à substituição tecnológica fundada no privilégio das TIC, que tem significado a já citada imposição de modelos supostamente aplicáveis a quaisquer situações, alternativas teórico-metodológicas precisam ser produzidas. Para remeter à apropriação das TIC, sem as amarras das práticas imediatistas e sem o privilégio da racionalidade técnica, este texto se encerra com um esboço de linhas de ação que retomam a perspectiva marxiana, explicitada na "Introdução de 1857" (Marx, 1957).

O caminho aqui esboçado assume a prática como seu ponto de partida e de chegada, submetendo ao seu crivo a elaboração teórica que sustenta a trajetória. Como contraposição ao conjunto das práticas inscritas nas formulações políticas que, por sua vez, tendem a ser "traduzidas" em instruções precisas de uso, é necessário analisar as condições de produção das práticas concretas, nas suas dimensões histórica e situacional.

Como os níveis macro e micro de análise são dimensionados relacionalmente, as alternativas de incorporação das TIC ao processo de trabalho docente, produzidas nos diferentes espaços pedagógicos, precisam ultrapassar a tendência à mera socialização das ditas "experiências bem-sucedidas". É fundamental a compreensão do que permite que elas sejam alçadas a esta condição; a sua objetivação em novas produções teóricas, a serem submetidas a outras provas práticas; e a sua inscrição em propostas pedagógicas que, sintonizadas com o momento presente, anunciem o futuro com outro horizonte.

Este outro horizonte implica o redimensionamento de formação e trabalho docente pela intervenção da crítica. Na medida da frequência desta escolha lexical aqui, é importante esclarecer que não se trata apenas de exigir que a crítica redunde em prática coerente, mas de submeter a crítica, bem como toda a elaboração teórica que com ela se relaciona dialeticamente, ao crivo da prática, ratificando e/ou retificando conceitos, para a transformação da prática concreta.

Para remeter ao caminho vislumbrado, algumas possibilidades são aqui intencionalmente expressas pelo gerúndio: pensando a universidade pública como espaço autônomo de produção de conhecimentos, em diálogo com as redes públicas; assumindo a escola como locus privilegiado, sem deixar de fora as questões que, 
embora a extrapolem, nela se corporificam; objetivando a docência como produção; propondo alternativas concretas, que não serão generalizadas, mas que podem favorecer trajetórias outras, através da análise das produções, na condição de produtos repostos como processos. Nos limites deste texto, centrado na apropriação das TIC, a finalidade é superar a perspectiva da substituição tecnológica, resgatando os sentidos da formação e do trabalho docente.

\section{Referências}

ANTUNES, R.; BRAGA, R. (Org.). Infoproletários: degradação real do trabalho virtual. São Paulo: Boitempo, 2009.

BARRETO, R.G. et al. As tecnologias da informação e da comunicação na formação de professores. Revista Brasileira de Educação, Rio de Janeiro, v. 11, n. 31, p. 31-42, 2006.

BARRETO, R.G. et al. “Que pobreza?!” Educação e tecnologias: leituras. Contrapontos, Itajaí, v. 11, n. 3, p. 185-202, set./dez. 2011.

BERNSTEIN, B. A estruturação do discurso pedagógico. Petrópolis: Vozes, 1996.

CANCLINI, N.G. Diferentes, desiguais e desconectados. Rio de Janeiro: UFRJ, 2005.

CASTELLS, M. A sociedade em rede - A era da informação: economia, sociedade e cultura. Rio de Janeiro: Paz \& Terra, 1999.

CHAUÍ, M. Ideologia neoliberal e universidade. In: OLIVEIRA, F.; PAOLI, M.C. (Org.). Os sentidos da democracia: políticas do dissenso e hegemonia global. Petrópolis: Vozes; Brasília, DF: Nedic, 1999. p. 27-51.

DRUCKER, P. A sociedade pós-capitalista. São Paulo: Pioneira, 2002.

FAIRCLOUGH, N. Discurso e mudança social. Brasília, DF: UnB, 2001.

FAIRCLOUGH, N. Language and globalization. London: Routledge, 2006.

FAIRCLOUGH, N. A dialética do discurso. Teias, Rio de Janeiro, v. 11, n. 22, 2010. Disponível em:<http://www.periodicos.proped.pro.br/index.php?journal=revistateias $>$. Acesso em: 12 set. 2010.

FELINTO, E. A religião das máquinas: ensaios sobre o imaginário da cibercultura. Porto Alegre: Sulina, 2005.

GALEANO, E. O teatro do bem e do mal. Porto Alegre: L\&PM, 2006.

GALVÃO, A.P.; COCCO, G.; SILVA, G. Capitalismo cognitivo: trabalho, redes e inovação. Rio de Janeiro: DP\&A, 2003. 
GRAMSCI, A. Os intelectuais e a organização da cultura. Rio de Janeiro: Civilização Brasileira, 1991.

ILLICH, I. Deschooling Society. Harmondsworth: Penguin, 1973.

LABARCA, G. Cuánto se puede gastar en educación? Revista de la Cepal, Santiago de Chile, n. 56, p. 163-178, ago. 1995.

LEHER, R. Para silenciar os campi. Educação E Sociedade, Campinas, v. 25, n. 88, p. 867-891, out. 2004.

LOJKINE, J. A revolução informacional. São Paulo: Cortez, 2002.

MARTIN-BARBERO, J. Dos meios às mediações: comunicação, cultura e hegemonia. Rio de Janeiro: UFRJ, 1997.

MARX, K. Contribuition à la critique de l'économie politique. Paris: Éditions Sociales, 1957.

MARX, K. O capital. 10. ed. São Paulo: Difel, 1985. Livro 1, v. 1.

MATTELART, A. História da sociedade da informação. São Paulo: Loyola, 2002.

SAVIANI, D. Pedagogia: o espaço da educação na universidade. Cadernos de Pesquisa, São Paulo, v. 37, n. 130, p. 99-134, jan./abr. 2007a.

SAVIANI, D. O Plano de Desenvolvimento da Educação: análise do Projeto do MEC. Educação E Sociedade, Campinas, v. 28, n. 100, p. 1231-1255, out. $2007 \mathrm{~b}$.

SCHAFF, A. A sociedade informática: as consequências sociais da segunda revolução industrial. São Paulo: Unesp; Brasiliense, 1995.

\section{Documentos analisados}

BRASIL. Câmara dos Deputados. Projeto de Lei n. 8.035/2010. Aprova o Plano Nacional de Educação para o decênio 2011-2020 e dá outras providências. Disponível em: <http://www.camara.gov.br/sileg/integras/831421.pdf>. Acesso em: 25 ago. 2011.

BRASIL. Lei n. 9.394, de 20 de dezembro de 1996. Estabelece as diretrizes e bases da educação nacional. Diário Oficial da União, Brasília, DF, 23 dez. 1996.

BRASIL. Lei n. 10.172, de 9 de janeiro de 2001. Aprova o Plano Nacional de Educação e dá outras providências. Diário Oficial da União, Brasília, DF, 10 jan. 2001. Disponível em: <https://www.planalto.gov.br/ccivil_03/leis/leis_2001/110172.htm>. Acesso em: 17 ago. 2011.

CONFERÊNCIA NACIONAL DE EDUCAÇÃO (CONAE). Construindo o Sistema Nacional Articulado de Educação: o Plano Nacional de Educação, diretrizes e estratégias; 
Documento Final. Brasília, DF: MEC; Conae, 2010. Disponível em: $<\mathrm{http} / /$ Conae. mec.gov.br/images/stories/pdf/pdf/doc_base_documento_final.pdf $>$. Acesso em: 12 jun. 2011.

UNESCO. Padrões de competências em TIC para professores: marco político. 2009. Disponível em: <www.unesdoc.unesco.org/images/0015/001562/156210por.pdf>. Acesso em: 30 ago. 2011.

WORLD BANK. Higher education in developing countries: peril and promise. 2000. Disponível em: <http://siteresources.worldbank.org/EDUCATION/Resources/2782001099079877269/547664-1099079956815/peril_promise_en.pdf>. Acesso em: 15 mar. 2011.

WORLD BANK. Constructing knowledge societies: new challenges for tertiary education. 2002. Disponível em: <http://web.worldbank.org/WBSITE/EXTERNAL/TOPICS/ EXTEDUCATION/0,,contentMDK:20283509 menuPK:617592 pagePK:148956 piP K:216618 theSitePK:282386,00.html>. Acesso em: 25 mar. 2011.

WORLD BANK. Lifelong learning in the global knowledge economy: challenges for developing countries. 2003. Disponível em: <http://web.worldbank.org/WBSITE/ EXTERNAL/TOPICS/EXTEDUCATION/0,,contentMDK:20283504 menuPK:617592 $\sim$ pagePK:148956 piPK:216618 theSitePK:282386,00.html>. Acesso em: 28 jun. 2011.

WORLD BANK. World Bank Education Strategy 2020: learning for all; investing in people's knowledge and skills to promote development. 2011. Disponível em: $<\mathrm{http}: / /$ web.worldbank.org/WBSITE/EXTERNAL/TOPICS/EXTEDUCATION/0,,contentM DK:22474207 menuPK:282402 pagePK:210058 piPK:210062 theSitePK:282386,00. html>. Acesso em: 12 ago. 2011.

WORLD TRADE ORGANIZATION (WTO). S/CSS/W/23, 2000. Disponível em: $<$ http://www.unesco.org/education/studyingabroad/highlights/global_forum/gats_ he/us.pdf>. Acesso em: 30 abr. 2011.

Recebido em 14 de outubro de 2011.

Aprovado em 11 de maio de 2012. 